\title{
JNPH
}

Volume 5 No. 2 (Desember 2017)

(C) The Author(s) 2017

\section{PENURUNAN KADAR BESI (Fe) DAN MANGAN (Mn) DENGAN KOMBINASI LIMBAH BATUBARA DAN LIMBAH TEMPURUNG KEMIRI DI SUMUR GALI WARGA PADANG SERAI KOTA BENGKULU}

\author{
A DECREASE IN THE LEVELS OF IRON (Fe) AND MANGANESE (Mn) WITH A \\ COMBINATION OF COAL WASTE AND WASTE SHELL PECANS IN \\ PADANG SERAI RESIDENTS DIG WELLS CITY OF BENGKULU
}

\author{
RIANG ADEKO, DEFI ERMAYENDRI \\ POLITEKNIK KESEHATAN KEMENTERIAN KESEHATAN BENGKULU \\ Jurusan Kesehatan Lingkungan \\ Email: keslingbkl@yahoo.com
}

\begin{abstract}
ABSTRAK
Air merupakan kebutuhan dasar bagi kehidupan, khususnya bagi manusia yang selama hidupnya selalu memerlukan air. Air digunakan oleh manusia untuk keperluan sehari-hari, seperti minum, mandi, cuci, kakus dan sebagainya. Kegunaan air yang sangat penting bagi manusia adalah untuk minum. Oleh karena itu, untuk keperluan minum, termasuk untuk masak, air harus mempunyai persyaratan khusus agar tidak menimbulkan penyakit pada manusia. Survey awal yang dilakukan pada tanggal 08 Februari 2017 di sumur gali warga RT.08 Kelurahan Padang Serai Kota Bengkulu setelah dilakukan pengukuran diperoleh Besi (Fe) 2,28 $\mathrm{mg} / \mathrm{L}$; Mangan $(\mathrm{Mn})$ 0,98 mg/L. Tujuan penelitian ini adalah untuk mengetahui penurunan kadar $\mathrm{Fe}$ dan $\mathrm{Mn}$ sebelum dan sesudah perlakuan dengan menggunakan variasi ketebalan batubara $20 \mathrm{~cm}, 30 \mathrm{~cm}$, dan $50 \mathrm{~cm}$ serta untuk mengetahui variasi ketebalan paling efektif untuk menurunkan kadar $\mathrm{Fe}$ dan $\mathrm{Mn}$. Jenis penelitian ini menggunakan metode eksperimen murni (True Experimental) dengan desain Post Test with control group ,yaitu penelitian dilakukan sebelum dan sesudah perlakuan dan kemudian dicari perbedaan antara pengukuran dari keduanya, serta perbedaan ini dianggap sebagai akibat perlakuan. Hasil penelitian yang dilakukan mulai dari survey awal yang dibandingkan dengan baku mutu air bersih untuk sumur gali warga dikawasan RT. 08 Kelurahan Padang Serai belum memenuhi persyaratan atau melebihi ambang batas baku mutu yang dianjurkan. Setelah dilakukan Eksperimen terjadi penurunan kadar Fe dengan menggunakan kombinasi batu bara dan tempurung kemiri sebesar $84,21 \%$ dan juga penurunan kadar Mn menggunakan kombinasi batu bara dan tempurung kemiri terjadi penurunan sebesar $69,38 \%$. Hasil penelitian diperoleh bahwa semakin tebal adsorben maka semakin efektif penurunannya.
\end{abstract}

Kata Kunci : adsorben, batu bara,tempurung kemiri sumur gali

\begin{abstract}
Water is a basic necessity for life, especially for humans who during his life always requires water. Water used by humans for everyday purposes, such as drinking, bathing, washing, latrines and so on. The usefulness of the water which is very important for human beings is to drink. Therefore, for the purposes of drinking, including Cook, water must have specific
\end{abstract}


requirements so as not to cause disease in humans. The initial survey conducted on 08 February 2017 in Wells gali residents Padang Serai Village 08 Town Bengkulu after done measurement obtained iron $(\mathrm{Fe}) 2.28 \mathrm{mg} / \mathrm{L}$; Manganese $(\mathrm{Mn}) 0.98 \mathrm{mg} / \mathrm{l}$. purpose of this research is to know the $\mathrm{Fe}$ and $\mathrm{Mn}$ levels before and after treatment by using a variation of coal thickness $20 \mathrm{~cm}, 30$ $\mathrm{cm}$ and $50 \mathrm{~cm}$, as well as to menegetahui the most effective thickness variation lower levels of $\mathrm{Fe}$ and $\mathrm{Mn}$. This type of research using the method of pure experimentation (True Experimental) with the design of the Post Test with control group, i.e. research conducted before and after the treatment and then look for the differences between the measurements of the both of them, and this distinction is considered as a result of the treatment. The results of the research conducted the survey starting from scratch compared to the raw quality of clean water to the well dig the lowliest citizen Padang Serai Village 08 do not meet or exceed the threshold requirement fledged quality is recommended. Once done the experiment happen levels decrease Fe using a combination of coal and shell the nuts of $84.21 \%$. and also decrease levels of Mn uses a combination of coal and shell the nuts took place decrease of $69.38 \%$. The research results obtained that the thicker the more effective adsorbents descents.

\section{Keywords: adsorbent, coal, pecans shell, well drilling}

\section{PENDAHULUAN}

Air merupakan kebutuhan dasar bagi kehidupan, khususnya bagi manusia yang selama hidupnya selalu memerlukan air. Air digunakan oleh manusia untuk keperluan sehari-hari, seperti minum, mandi, cuci, kakus dan sebagainya. Kegunaan air yang sangat penting bagi manusia adalah untuk minum. Oleh karena itu, untuk keperluan minum, termasuk untuk masak, air harus mempunyai persyaratan khusus agar tidak menimbulkan penyakit pada manusia (Soemirat, 2011).

Air bersih adalah air yang digunakan untuk keperluan sehari-hari yang kualitasnya memenuhi syarat kesehatan dan dapat diminum apabila telah dimasak (Depkes RI, 2017).

Ditinjau dari segi kualitas, air harus memenuhi beberapa syarat kesehatan baik fisik, bakteorologis, kimiawi, maupun radioaktif (Keputusan Menteri Kesehatan RI No.907/Menkes/SK/VII/2002).

Sumber air dapat diklasifikasikan kedalam beberapa jenis sumber air yaitu air hujan,air permukaan air tanah,dan air laut.Masing-masing sumber air tersebut secara alamiah memiliki karakteristik kualitas air tersendiri, hal ini terjadi karena kualitas air sangat dipengaruhi oleh keadaan alam tempat air tersebut berada dan kondisi tempat-tempat yang dilaluinya. Didaerah perkotaan penduduk yang tidak memperoleh pelayanan air ledeng, sebagian besar menggunakan sumber air tanah baik berupa sumur gali maupun sumur pompa sebagai sumber air bersihnya. Sumber air tanah dipilih karena relatif lebih baik dari air sungai ditinjau dari segi kualitasnya terutama faktor kekeruhannya. Air tanah sebagai sumber air bersih pada umumnya dapat langsung digunakan untuk kehidupan sehari-hari. Namun tanpa disadari bahwa air tanah mengandung banyak unsur logam yang terlarut dalam air, diantaranya $\mathrm{Fe}$ dan $\mathrm{Mn}$ (Aba, 2017).

Berdasarkan survey awal yang dilakukan pada tanggal 08 Februari 2017 di sumur gali warga RT. 08 Kelurahan Padang Serai Kota Bengkulu setelah dilakukan pengukuran diperoleh Besi (Fe) 2,28 mg/L; Mangan (Mn) $0,98 \mathrm{mg} / \mathrm{L}$. Hasil pengukuran pada survey awal diketahui bahwa air sumur gali warga RT. 08 Kelurahan Padang Serai Kota Bengkulu masih melebihi ambang batas yang dipersyaratkan oleh Permenkes RI No.32 Tahun 2017.

Mengatasi masalah tersebut, perlu dilakukan proses penjernihan air dengan membuat suatu alat penjernihan dengan media yang mudah di peroleh dipasaran yaitu karbon aktif. Karbon aktif dipilih karena mampu dalam proses penyerapan zat organik maupun anorganik, sebagai penukar kation 
dan katalis untuk berbagai reaksi. Bahan baku yang akan dikembangkan sebagai karbon aktif adalah limbah batu bara yang dikombinasikan dengan limbah tempurung kemiri. Limbah batu bara merupakan hasil buangan proses pengolahan pada industri batu bara dan limbah tempurung kemiri juga merupakan hasil buangan dari usaha hasil bumi sehingga berdampak pada pencermaran lingkungan.

\section{METODE PENELITIAN}

Jenis penelitian yang digunakan adalah eksperimen murni (True Experimental) dengan desain post test with control group yaitu penelitian dilakukan sebelum dan sesudah perlakuan. Kemudian dicari perbedaan antara pengukuran dari keduanya dan perbedaan ini dianggap sebagai akibat perlakuan.

Lokasi penelitian pada sumur gali warga RT. 08 Kelurahan Padang Serai Kota Bengkulu dengan alokasi waktu penelitian selama 3 bulan.

\section{HASIL PENELITIAN}

Penelitian ini dilakukan di Workshop Jurusan Kesehatan Lingkungan pada bulan Oktober sampai dengan November 2017, bertujuan untuk mengetahui efektivitas kombinasi limbah batu bara dan tempurung kemiri sebagai adsorben untuk menurunkan kadar Fe dan Mn di sumur gali warga RT. 08 Kelurahan Padang Serai Kota Bengkulu.

Hasil pengukuran kadar Fe dan Mn pada berbagai ketebalan media dan lama kontak disajikan dalam bentuk data yang akan diuji secara statistik.

Tabel 1 Rata-rata kadar Fe air bersih Padang Serai

\begin{tabular}{|c|c|c|c|c|c|c|}
\hline \multirow[b]{2}{*}{$\begin{array}{l}\text { Perla- } \\
\text { kuan } 1\end{array}$} & \multirow{2}{*}{$\begin{array}{c}\text { Keteba- } \\
\text { lan }\end{array}$} & \multirow[t]{2}{*}{$\mathrm{N}$ Mean } & \multirow[t]{2}{*}{ Low } & \multirow[t]{2}{*}{ Up } & \multirow[t]{2}{*}{ Min } & \multirow[t]{2}{*}{ Max } \\
\hline & & & & & & \\
\hline \multirow[t]{2}{*}{$\mathrm{Fe}$} & $50: 50 \mathrm{~cm}$ & 50,360 & 0,248 & 0,47 & 0,23 & 0,45 \\
\hline & & 0 & 3 & 7 & & \\
\hline
\end{tabular}

\begin{tabular}{ccccccc}
\hline $30: 30 \mathrm{~cm}$ & 5 & 0,852 & $0,6381,065$ & 0,74 & 1,15 \\
\multicolumn{5}{c}{0} & 3 & 7 \\
\cline { 2 - 6 } & 0 & 7 & 3 & \\
\hline Control & 5 & 2,280 & $2,6012,601$ & 2,00 & 2,50 \\
\multicolumn{5}{c}{0} & 4 & 4 \\
\hline
\end{tabular}

Berdasarkan tabel 1 rata-rata penurunan Fe adalah $0,360 \mathrm{mg} / \mathrm{l}$. Rerata terendah adalah $0,23 \mathrm{mg} / 1$ dan tertinggi 0,45 dengan tingkat kepercayaan $95 \%$ atau signifikansi 5\%, ratarata penurunan pada range $0,2483 \mathrm{mg} / 1$ sampai dengan $0,4717 \mathrm{mg} / \mathrm{l}$.

Tabel 2 Rata-rata Kadar Mn Air Bersih Padang Serai

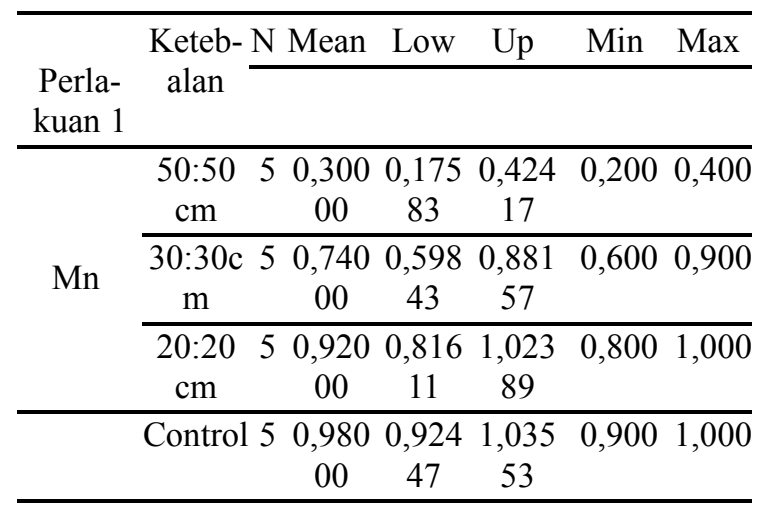

Berdasarkan tabel 2 rata-rata penurunan Mn adalah 0,3000 mg/l. Rerata terendah adalah $0,200 \mathrm{mg} / \mathrm{l}$ dan tertinggi 0,400 dengan tingkat kepercayaan $95 \%$ atau signifikansi $5 \%$, rata-rata penurunan pada range 0,17583 $\mathrm{mg} / \mathrm{l}$ sampai dengan $0,42417 \mathrm{mg} / \mathrm{l}$.

Untuk mengetahui perbedaan tingkat penurunan kadar Fe dan Mn pada masingmasing perlakuan dengan menggunakan uji One way Anova dengan dilakukan uji Onesample Kolmogorov-Smirov Test hasil uji One-sample Kolmogorov-Smirov Test dengan Sig. (2-tailed) didapat hasil pada Kadar Fe adalah 0,588 dan $\mathrm{Mn}$ adalah 0,295. Ini menunjukkan bahwa data yang normal sehingga bisa dilanjutkan ke Uji Oneway Anova dan tes homogenitas uji yang dilakukan Levene Test Hitung $\mathrm{Fe}$ adalah 3,118 dengan probabilitas $(\alpha)$ 0,56 dan $\mathrm{Mn}$ 1,549 dengan probabilitas $(\alpha) 0,241$. Oleh karena probabilitas $(\alpha)>0,05$ maka Ho 
diterima atau semua perlakuan memiliki variasi yang sama.

Terlihat pada tabel 3 bahwa $\mathrm{F}$ hitung $\mathrm{Fe}$ adalah 103,063 dengan Probabilitas $(\alpha)$ 0,000 dan F hitung Mn 59,063 dengan Probabilitas $(\alpha) 0,000$, maka probabilitas $(\alpha)<0,05$, maka Ho ditolak atau rata rata penurunan perlakuan tersebut memang berbeda nyata. Setelah diketahui perbedaan yang signifikan, selanjutnya akan dibahas dengan pada analisis Bonferroni dan tukey dalam post hoc test

Tabel 3 Uji Anova digunakan Untuk pengujian lebih dari dua perlakuan

\begin{tabular}{ccccccc}
\hline & & $\begin{array}{c}\text { Sum of } \\
\text { Square }\end{array}$ & df & $\begin{array}{c}\text { Mean } \\
\text { Square }\end{array}$ & F & Sig \\
\hline Fe & Between & 9,948 & 3 & 3,316 & 103,060 & 0,000 \\
& Group & 0,515 & 16 & 0,32 & & \\
Within & 10,463 & 19 & & & \\
group & & & & & \\
& Total & & & & & \\
\hline Mn & Between & 1,418 & 3 & 0,473 & 59,063 & 0,000 \\
& Group & 0,128 & 16 & 0,008 & & \\
& Within & 1,546 & 19 & & & \\
group & & & & & & \\
Total & & & & & &
\end{tabular}

Pada tabel 4 diketahui $\mathrm{p}$ value $=0,000$ sehingga $\mathrm{p}<\alpha(0,05)$ maka $\mathrm{H} 0$ ditolak dan Ha diterima atau ada pengaruh yang signifikan variasi ketebalan dalam penurunan kadar $\mathrm{Fe}$ dan Mn. Namun hanya pada Penyaringan Mn dengan perlakuan 20:20 yang memiliki nilai $\alpha>0,05$ sehingga tidak ada pengaruh yang signifikan terhadap penurunan kadar Mn.

Tabel 4 Tabel Hasil Uji Bonferoni

\begin{tabular}{ccccc}
\hline \multicolumn{2}{l}{$\begin{array}{c}\text { Variable Perlakuan } \\
(\mathrm{I})\end{array}$} & $\begin{array}{c}\text { Perlakuan } \\
(\mathrm{j})\end{array}$ & $\begin{array}{c}\text { Mean } \\
\text { Diffrence }\end{array}$ & Sig \\
\hline $\mathrm{Fe}$ & $50: 50$ & $30: 30$ & 0,49200 & 0,03 \\
& & $20: 20$ & 0,82600 & 0,00 \\
& & Control & $-1,92000$ & 0,00 \\
\hline & $30: 30$ & $20: 20$ & 0,33400 & 0,57 \\
& & Control & $-1,42800$ & 0,000 \\
\hline & $20: 20$ & Control & $-1,09400$ & 0,000 \\
\hline $\mathrm{Mn}$ & $50: 50$ & $30: 30$ &,- 440000 & 0,000 \\
& & $20: 20$ &,- 620000 & 0,000 \\
& & Control &,- 680000 & 0,000 \\
\hline & $30: 30$ & $20: 20$ &,- 180000 & 0,035 \\
\hline
\end{tabular}

\begin{tabular}{cccc}
\hline & Control &,- 240000 & 0,04 \\
\hline $20: 20$ & Control &,- 060000 & 1,000 \\
\hline
\end{tabular}

\section{PEMBAHASAN}

Berdasarkan hasil uji One way Anova diketahui bahwa masing-masing perlakuan dengan menggunakan variasi ketebalan kombinasi batu bara dan tempurung kemiri terhadap penurunan kadar $\mathrm{Fe}$ dan $\mathrm{Mn}$ memiliki penurunan yang berbeda beda. Hasil analisis univariat menunjukkan bahwa perlakuan ketiga memiliki tingkatan penurunan yang paling efektif. Semakin tebal koombinasi batu bara dan tempurung kemiri yang digunakan maka semakin efektif dalam menurunkan kadar Fe dan Mn.

\section{Hasil uji laboratorium menunjukkan :}

\section{Penurunan kadar $\mathrm{Fe}$ dengan variasi ketebalan kombinasi batu bara dan tempurung kemiri}

Berdasarkan hasil analisis diperoleh bahwa kandungan $\mathrm{Fe}$ pada penyaringan dengan menggunakan kombinasi batu bara dan tempurung kemiri pemeriksaaan control adalah $2,28 \mathrm{mg} / \mathrm{l}$. Hasil atau terjadi penurunan sekitar 84,21 \%. Hasil ini menunjukkan bahwa kombinasi batu bara dan tempurung kemiri berpengaruh terhadap penurunan kadar Fe dalam air. Batu bara merupakan batuan sedimen yang secara kimia dan fisika adalah heterogen dan mengandung unsur-unsur karbon, hidrogen dan oksigen sebagai unsur utama dan belerang serta nitrogen sebagai unsur tambahan. Zat lain, yaitu senyawa organik pembentuk "ash" tersebar sebagai partikel zat mineral dan terpisah-pisah di seluruh senyawa batubara sedangkan tempurung kemiri memiliki karakteristik sifat yang keras dengan permukaan yang kasar dan beralur. Tempurung ini sangat cocok untuk dijadikan bahan baku dari karbon aktif karena memiliki kandungan selulose, hemiselulose, dan lignin.

\section{Penurunan kadar Mn dengan variasi}




\section{kombinasi batu bara dan tempurung kemiri}

Berdasarkan hasil analisis diperoleh bahwa kandungan $\mathrm{Mn}$ pada penyaringan dengan menggunakan batu bara pemeriksaaan control adalah $0,98 \mathrm{mg} / \mathrm{l}$. Hasil atau terjadi penurunan sekitar 69,38\%. Hasil ini menunjukkan bahwa kombinasi batu bara dan tempurung kemiri berpengaruh terhadap penurunan kadar Mn dalam air. Batu bara merupakan batuan sedimen yang secara kimia dan fisika adalah heterogen dan mengandung unsur-unsur karbon, hidrogen dan oksigen sebagai unsur utama dan belerang serta nitrogen sebagai unsur tambahan. Zat lain, yaitu senyawa organik pembentuk "ash" tersebar sebagai partikel zat mineral dan terpisah-pisah diseluruh senyawa batubara sedangkan tempurung kemiri memiliki karakteristik sifat yang keras dengan permukaan yang kasar dan beralur. Tempurung ini sangat cocok untuk dijadikan bahan baku dari karbon aktif karena memiliki kandungan selulose, hemiselulose, dan lignin.

Berdasarkan hasil pengujian secara keseluruhan dengan menggunakan variasi ketebalan kombinasi batubara dan tempurung kemiri $20 \mathrm{~cm}, 30 \mathrm{~cm}, 50 \mathrm{~cm}$, diketahui bahwa air sumur gali warga RT. 08 Kelurahan Padang Serai Kota Bengkulu telah sesuai dengan persyaratkan oleh Permenkes RI No.32 Tahun 2017.

\section{KESIMPULAN}

Hasil penelitian yang telah dilakukan, dapat diambil simpulan sebagai berikut:

1. Media kombinasi batu bara dan tempurung kemiri dengan ketebalan.

2. $50 \mathrm{~cm}$ dapat menurunkan kadar Fe hingga $84,21 \%$.

3. Media kombinasi batu bara dan tempurung kemiri dengan ketebalan $50 \mathrm{~cm}$ dapat menurunkan kadar Mn hingga 69,38\%.

\section{SARAN}

Bagi ilmu pengetahuan institusi pendidikan/akademik, penelitian ini dapat diterapkan untuk mengolah limbah cair kimia laboratorium dan dapat digunakan sebagai bahan pembelajaran pada mata kuliah PAPLC (pengolahan air dan pengolahan limbah cair).

\section{DAFTAR PUSTAKA}

Aba,dkk (2017). Pengolahan Air Sumur Gali Dengan Metode Aerasi-Filtrasi Menggunakan Aerator Gelembung Dan Saringan Pasir Cepat Untuk Menurunkan Kadar Besi (Fe) Dan Mangan (Mn), Jurnal Aplikasi Fisika Volume 13 Nomor 2 Juni 2017

Chandra Budiman. 2007. Pengantar Kesehatan Lingkungan. Jakarta : EGC

Departemen Kesehatan RI, 2002. Keputusan Menteri Kesehatan No. 907/MENKES/SK/VII/2002 tentang Syarat-Syarat dan Pengawasan Kualitas Air . Jakarta: Departemen Kesehatan RI.

Depkes RI. 2017. Permenkes RI No.32 Tahun 2017. tentang Standar Baku Mutu Kesehatan Lingkungan Dan Persyaratan Kesehatan Air Untuk Keperluan Higiene Sanitasi, Kolam Renang, Solus Per Aqua, Dan Pemandian Umum. Jakarta: Departemen Kesehatan RI.

Soemirat, J. 2011. Kesehatan Lingkungan. Revisi. Yogyakarta: Gadja Mada University Press. 